\title{
Infecção bacteriana na leishmaniose cutânea: padrão bacteriano e sensibilidade a antibióticos
}

\author{
Bacterial infection in cutaneous leishmaniasis: \\ bacterial pattern and sensitivity to antibiotics
}

\author{
Eloísa da Graça do Rosário Gonçalves ${ }^{1}$, Stelito Assis dos Reis Filho², \\ Eurípedes Gomes de Oliveira ${ }^{2}$, André Luiz Neves Pareira ${ }^{3}$, Antonio Rafael da Silva ${ }^{1}$ \\ e Jackson Maurício Lopes Costa ${ }^{4}$
}

\begin{abstract}
RESUMO
Foi estudada a flora bacteriana em úlceras leishmanióticas, destacando-se o encontro das espécies aeróbicas Staphylococus aureus e Pseudomonas aeruginosa. 0 estudo da sensibilidade destas espécies a antibióticos mostrou sensibilidade à vancomicina, à amicacina e ao cloranfenicol em $100 \%$ dos isolados testados de Staphylococus aureus e à amicacina, à gentamicina e à tobramicina em $100 \%$ dos isolados testados de Pseudomonas aeruginosa. Estas espécies foram, em geral, resistentes às penicilinas e à tetraciclina.
\end{abstract}

Palavras-chaves: Leishmaniose tegumentar. Bactérias. Sensibilidade a antibióticos.

\begin{abstract}
The bacterial flora from leishmanial ulcers was studied. The aerobic species Staphylococcus aureus and Pseudomonas aeruginosa were found most frequently. Evaluation of the sensitivity of these species to antibiotics showed that $100 \%$ of these isolates of Staphylococcus aureus were sensitive to vancomycin, amikacin and chloramphenicol, while $100 \%$ of the isolates of Pseudomonas aeruginosa were sensitive to amikacin, gentamicin and tobramycin. These species were generally resistant to penicillins and tetracycline.
\end{abstract}

Key-words: Cutaneous leishmaniasis. Bacteria. Sensitivity to antibiotics.

A forma cutânea típica da leishmaniose tegumentar (LT) surge no local da picada do vetor (flebotomíneo), em áreas expostas do corpo. De pequena pápula inicial, tende a ulcerar apresentando bordas elevadas, em moldura e fundo granuloso, em geral, indolor. Infecção bacteriana secundária, no entanto, tem sido observada com frequiência em pacientes atendidos na rotina dos ambulatórios do Centro de Referência em Doenças Infecciosas e Parasitárias (CRDIP) e do Núcleo de Estudos em Medicina Tropical da Pré-Amazônia (NEMTPA), ambos da Universidade Federal do Maranhão (UFMA), localizados em São Luis e Buriticupu-MA, respectivamente. Embora não tenha sido demonstrada influência direta de infecção secundária na evolução e desfecho da LT por outros autores $^{4}$, o conjunto de sinais e sintomas resultantes do processo (dor, edema e vermelhidão, associados à presença de

1. Centro de Referência em Doenças Infecciosas e Parasitárias, Departamento de Patologia, Universidade Federal do Maranhão, São Luís, MA. 2. Disciplina de Microbiologia, Departamento de Patologia, Universidade Federal do Maranhão, São Luis, MA. 3. Curso de Medicina, Universidade Federal do Maranhão, São Luis, MA. 4. Centro de Pesquisas Gonçalo Muniz, Fundação Oswaldo Cruz, Salvador, BA. Endereço para correspondência: Dra. Eloísa da Graça do Rosário Gonçalves. Dept $^{0}$ de Patologia/UFMA. Praça Madre Deus 02, Térreo, Bairro Madre Deus, 65025-560 São Luis, MA.

Tel: 5598 3221-0270

e-mail: regionalsbmt@elo.com.br

Recebido para publicação em 04/09/2008

Aceito em 20/03/2009 secreção amarelada e/ou crostas melicéricas) parecem constituir um fator adicional de morbidade, requerendo tratamento específico. Em vista disso, e levando-se em conta a elevada prevalência da doença no Estado do Maranhão, desenvolveu-se este estudo, que teve por objetivos identificar as espécies bacterianas aeróbicas nas lesões ulceradas, bem como estudar a sensibilidade in vitro das espécies isoladas a antibióticos.

Foram selecionados, nos anos de 1998 e 1999, 37 pacientes com diagnóstico definido de LT, pela demonstração de formas amastigotas de Leishmania sp em raspado da lesão, corado pelo método de Giemsa ou em material de biópsia e que, no momento do exame físico, apresentassem os sinais clínicos de infecção bacteriana.

Aqueles que tinham feito uso tópico ou sistêmico de antimicrobianos foram excluídos do estudo. A caracterização do grupo selecionado mostra que 24 indivíduos pertenciam ao sexo masculino e 13 , a feminino. A idade dos pacientes variou de 11 a 78 anos, sendo a faixa etária mais acometida a de 10 a 39 anos, com $29(78,4 \%)$ casos. A ocupação mais freqüente foi a de lavrador, referida por 17 (45,9\%) indivíduos, seguida de estudantes com 8 (21,5\%), militares em treinamento, com $4(10,8 \%)$, pessoas com atividades domésticas com 3 (8,1\%) e operários com $3(8,1 \%)$ casos. Outras ocupações referidas foram professor e comerciante. 
Todos os pacientes exibiam a forma ulcerada típica da LT, não havendo envolvimento mucoso em nenhum. A observação do número de lesões mostrou que 23 pacientes tinham lesão única e 14, lesões múltiplas. As lesões cutâneas estavam presentes nos membros inferiores em 20 pacientes, nos membros superiores, em nove, e na região cervical ou na cabeça, em três. Em cinco, havia úlceras em mais de um segmento corporal.

0 material destinado ao isolamento e identificação de espécies bacterianas foi obtido das bordas e do centro das lesões ulceradas, empregando-se swab, após limpeza com soro fisiológico estéril e mantido em meio de transporte de Cary e Blair até o processamento laboratorial, o que se deu no prazo de, no máximo, 72 horas. Foram empregados os meios de agarsangue e agar-MacConkey para o isolamento bacteriano e provas bioquímicas, para a identificação.

0 estudo da sensibilidade bacteriana a antibióticos foi feito pelo método de difusão do antibiótico, segundo Kirby-Bauer, testando-se discos impregnados de antibióticos para bactérias Gram-negativas e Gram-positivas, do laboratório CECON.

0 estudo microbiológico permitiu o isolamento e identificação de uma flora bacteriana composta por bactérias aeróbicas do material obtido de 30 pacientes, destacando-se como mais frequientes as espécies Gram-positivas, Staphylococcus aureus (16 pacientes) e Staphylococcus saprophyticus (2 pacientes) e as Gram-negativas, Pseudomonas aeruginosa (10 pacientes) e Klebsiella pneumoniae (6 pacientes), conforme mostrado nas Tabelas 1 e 2. No material de 7 pacientes, não houve crescimento bacteriano. Enterobacter cloacae foi isolado da lesão de um paciente e Staphylococcus epidermidis de dois pacientes, não tendo sido estas espécies submetidas aos testes de sensibilidade a antibióticos.

No estudo da sensibilidade a antibióticos, destaca-se que Staphylococcus aureus mostrou sensibilidade em 100\% das amostras testadas à amicacina e à vancomicina, 93,7\% ao cloranfenicol e 56,2\% à tetraciclina. Houve resistência em 87,5\% das amostras à penicilina; Staphylococus saprophyticus mostrou 100\% de sensibilidade à vancomicina, à amicacina e ao cloranfenicol; 50\% de sensibilidade à penicilina e resistência à tetraciclina (Tabela 1).
Todas as amostras de Pseudomonas aeruginosa testadas foram sensíveis aos aminoglicosídeos (amicacina, gentamicina e tobramicina); por outro lado, houve resistência em $90 \%$ à ampicilina e à cefoxitina; em $80 \%$ à tetraciclina e em $70 \%$ ao cloranfenicol. Das seis amostras de Klebsiella pneumoniae testadas, $100 \%$ foram sensíveis aos aminoglicosídeos (amicacina, gentamicina e tobramicina), ao cloranfenicol e à tetraciclina; 83,3\% à ampicilina e 66,6\% à cefoxitina (Tabela 2).

A leishmaniose tegumentar é doença endêmica na região da pré-Amazônia do Estado do Maranhão, onde foi descrito surto epidêmico com 300 casos em 1979, com predominância de casos em indivíduos adultos, do sexo masculino que exerciam atividades em ambiente silvestre e/ou agrícola, emprestando à doença caráter ocupacional 5 . Com a intensificação do processo de desmatamento na região, o padrão epidemiológico tende a se modificar, com o surgimento da doença em indivíduos de faixa etária mais jovem e no sexo feminino, sugerindo transmissão peridomiciliar $^{13}$. Tal fato poderia justificar a ocorrência da doença em número expressivo de estudantes e pessoas com atividades domésticas encontradas no estudo.

A decisão de incluir apenas pacientes com a forma ulcerada clássica visou reduzir erros na interpretação dos resultados, de modo que este estudo pudesse constituir uma base de referência para outras observações, em andamento no Centro de Referência em Doenças Infecciosas e Parasitárias. A distribuição das lesões por segmento corporal, bem como o número de lesões por paciente, apresentados na amostra estudada, traduzem o

\section{TABELA 1}

Freqüiencia e percentual de isolados de bactérias Gram-positivas de úlceras leishmanióticas sensíveis a antibióticos, Estado do Maranhão, 1999.

\begin{tabular}{lccccc}
\hline & \multicolumn{2}{c}{$\begin{array}{c}\text { Staphylococcus } \\
\text { aureus }\left(\mathrm{n}^{\circ}=16\right)\end{array}$} & & \multicolumn{2}{c}{$\begin{array}{c}\text { Staphylococcus } \\
\text { saprophyticus }\left(\mathrm{n}^{\circ}=2\right)\end{array}$} \\
\cline { 2 - 3 } Antibiótico testado & $\mathrm{n}^{0}$ & $\%$ & & $\mathrm{n}^{0}$ & $\%$ \\
\hline Penicilina & 2 & 12,5 & & 50,0 \\
Tetraciclina & 9 & 56,2 & $\mathrm{NT}$ & - \\
Cloranfenicol & 15 & 93,7 & & 2 & 100,0 \\
Vancomicina & 16 & 100,0 & & 1 & 50,0 \\
Amicacina & 16 & 100,0 & & 2 & 100,0 \\
\hline
\end{tabular}

NT: não testado

TABELA 2

Frequiência e percentual de isolados de bactérias Gram-negativas de úlceras leishmanióticas sensíveis a antibióticos, Estado do Maranhão, 1999.

\begin{tabular}{|c|c|c|c|c|c|c|c|c|c|c|c|c|c|c|c|c|c|c|}
\hline \multirow{2}{*}{$\begin{array}{l}\text { Antibiótico } \\
\text { testado }\end{array}$} & \multicolumn{2}{|c|}{$\begin{array}{c}\text { Pseudomonas } \\
\text { aeruginosa }\end{array}$} & \multicolumn{2}{|c|}{$\begin{array}{c}\text { Klebsiella } \\
\text { pneumoniae }\end{array}$} & \multicolumn{2}{|c|}{$\begin{array}{c}\text { Serratia } \\
\text { liquefascies }\end{array}$} & \multicolumn{2}{|c|}{$\begin{array}{c}\text { Escherichia } \\
\text { coli }\end{array}$} & \multicolumn{2}{|c|}{$\begin{array}{c}\text { Morganella } \\
\text { morganii }\end{array}$} & \multicolumn{2}{|c|}{$\begin{array}{c}\text { Proteus } \\
\text { mirabilis }\end{array}$} & \multicolumn{2}{|c|}{$\begin{array}{r}\text { Hafnia } \\
\text { alveri }\end{array}$} & \multicolumn{2}{|c|}{$\begin{array}{c}\text { Enterobacter } \\
\text { aerogenes }\end{array}$} & \multicolumn{2}{|c|}{$\begin{array}{c}\text { Citrobacter } \\
\text { freundii }\end{array}$} \\
\hline & $\mathrm{n}^{\underline{0}}$ & $\%$ & $\mathrm{n}^{0}$ & $\%$ & $\overline{\mathrm{n}^{0}}$ & $\%$ & $\overline{\mathrm{n}^{0}}$ & $\%$ & $\mathrm{n}^{0}$ & $\%$ & $\mathrm{n}^{0}$ & $\%$ & $\mathrm{n}^{0}$ & $\%$ & $\mathrm{n}^{\mathrm{o}}$ & $\%$ & $\mathrm{n}^{0}$ & $\%$ \\
\hline Amicacina & 10 & 100,0 & 6 & 100,0 & 3 & 100,0 & 2 & 66,6 & 1 & 100,0 & 1 & 100,0 & 1 & 100,0 & 1 & 100,0 & 1 & 100,0 \\
\hline Gentamicina & 10 & 100,0 & 6 & 100,0 & 3 & 100,0 & 2 & 66,6 & 1 & 100,0 & 1 & 100,0 & 1 & 100,0 & 1 & 100,0 & 0 & 0,0 \\
\hline Tobramicina & 10 & 100,0 & 6 & 100,0 & 3 & 100,0 & 3 & 100,0 & 1 & 100,0 & NT & - & 1 & 100,0 & 1 & 100,0 & 1 & 100,0 \\
\hline Cloranfenicol & 3 & 30,0 & 6 & 100,0 & 3 & 100,0 & 0 & 0,0 & 0 & 0,0 & 1 & 100,0 & 1 & 100,0 & 1 & 100,0 & 1 & 100,0 \\
\hline Tetraciclina & 2 & 20,0 & 6 & 100,0 & 3 & 100,0 & 1 & 33,3 & 0 & 0,0 & 0 & 0,0 & 1 & 100,0 & 1 & 100,0 & NT & - \\
\hline Cefoxitina & 1 & 10,0 & 4 & 66,6 & 0 & 0,0 & 2 & 66,6 & 1 & 100,0 & NT & - & 1 & 100,0 & 0 & 0,0 & 0 & 0,0 \\
\hline Ampicilina & 1 & 10,0 & 5 & 83,3 & 0 & 0,0 & 0 & 0,0 & 0 & 0,0 & 0 & 0,0 & 0 & 0,0 & 0 & 0,0 & 0 & 0,0 \\
\hline
\end{tabular}

NT: não testado. 
perfil clínico da LT nos serviços referidos e em outras regiões do país $^{16}$. 0 método empregado para a obtenção dos espécimes clínicos, com o uso de swab, tem a limitação de obter material apenas da superfície das lesões, o que pode tornar imprecisa a diferenciação entre infecção e colonização das úlceras ${ }^{6}$. Apesar disso, o estudo permitiu o isolamento e identificação de uma flora composta por uma diversidade grande de espécies bacterianas, com destaque para Staphylococcus aureus como a bactéria mais freqüente o que está de acordo com as observações de outros autores ${ }^{27}$. Chama-se a atenção, ainda, para o encontro de Pseudomonas aeruginosa em significativo número de amostras. 0 perfil de sensibilidade aos antibióticos corrobora, em geral, os resultados encontrados por outros autores em relação aos aminoglicosídeos, vancomicina, e tetraciclina ${ }^{6}$, não tendo sido avaliada a ação de sulfamídicos, quinolonas e cafalosporinas de terceira geração neste estudo inicial.

\section{REFERÊNCIAS}

1. Costa JML, Balby ITA, Rocha EJS, Silva AR, Rebelo JMM, Ferreira LA, Gama MEA, Branco MRFC, Buratini MN, Soares NJS. Estudo comparativo da leishmaniose tegumentar americana em crianças e adolescentes procedentes das áreas endêmicas de Buriticupu (MA) e Corte de Pedra (BA), Brasil. Revista da Sociedade Brasileira de Medicina Tropical 31: 279-288, 1998.

2. Edrissian GH, Mohammadi M, Kanani A, Afshar A, Hafezi R, Ghorbani M, Gharagozloo AR. Bacterial infections in suspected cutaneous leishmaniasis lesions. Bulletin of the World Health Organization 68: 473-477, 1990.

3. Martins LM, Rebelo JMM, Santos MCFV, Costa JML, Silva AR, Ferreira LA. Ecoepidemiologia da leishmaniose tegumentar no município de Buriticupu, Amazônia do Maranhão, Brasil, 1996 a 1998. Cadernos de Saúde Pública 20: 735-743, 2004.

4. Oliveira MR, Tafuri WL, Nicoli JR, Vieira EC, Melo MN, Vieira LQ. Influence of microbiota in experimental cutaneous leishmaniasis in Swiss mice. Revista do Instituto de Medicina Tropical de São Paulo 41: 87-94, 1999.

5. Silva AR, Martins G, Mello JEM, Araújo JP, Mendes JR, Mendes MG. Surto epidêmico de leishmaniose tegumentar americana ocorrido na colonização agrícola de Buriticupu (Estado do Maranhão), Brasil. Revista do Instituto de Medicina Tropical de São Paulo 21: 43-50, 1979.

6. Veras LA, Macedo JLS, Ciuffo IA, Santos CG, Santos JB. Sensibilidade antimicrobiana de bactérias aeróbias isoladas de úlceras leishmanióticas, em Corte de Pedra, BA. Revista da Sociedade Brasileira de Medicina Tropical 39: 47-50, 2006 .

7. Veras LA, Santos JB, Macedo VO, Magalhães AV, Ciuffo IA, Santos CG. Avaliação da influência da infecção bacteriana secundária na evolução da leishmaniose cutânea em Corte de Pedra, BA. Revista da Sociedade Brasileira de Medicina Tropical 34: 233-237, 2001. 